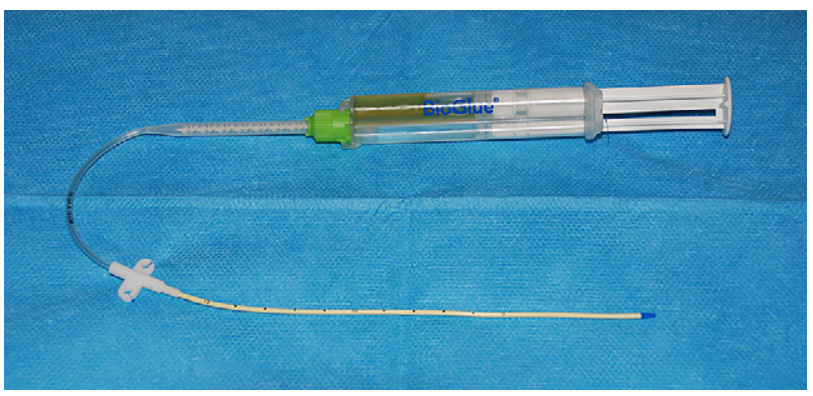

FIGURE 1. Single-lumen catheter.

pneumonectomy, had uncontrollable bleeding from many pleural systemic collaterals.

From 2008 onward, PEA has been applied even in 10 patients for the treatment of pulmonary artery sarcoma. In this peculiar population, air bubbles were noticed more frequently (3/10), probably because the obstructive material is absolutely different in nature and the arterial wall is less strong compared with thromboembolic lesions. Surgical adhesive delivery successfully prevented pulmonary hemorrhage in all patients.
The "bubble" technique has been useful for defining the etiology of airway bleeding intraoperatively and for starting the proper treatment without delay. The identification of an arterial disruption during hypothermic circulatory arrest allows the surgeon to operate immediately. The loss of time caused by the patient's rewarming would be avoided, as well as patient recooling if a surgical repair could be attempted.

\section{References}

1. Mayer E, Jenkins D, Lindner J, D’Armini A, Kloek J, Meyns B, et al. Surgical management and outcome of patients with chronic thromboembolic pulmonary hypertension: results from an international prospective registry. J Thorac Cardiovasc Surg. 2011;141:702-10.

2. Manecke GR Jr, Kotzur A, Atkins G, Fedullo PF, Auger WR, Kapelanski DP, et al. Massive pulmonary hemorrhage after pulmonary thromboendarterectomy. Anesth Analg. 2004;99:672-5.

3. Pretorius V, Alayadhi W, Modry D. Extracorporeal life support for the control of life-threatening pulmonary hemorrage. Ann Thorac Surg. 2009;88: 649-50.

4. Morsolini M, Nicolardi S, Milanesi E, Sarchi E, Mattiucci G, Klersy C, et al. Evolving surgical techniques for pulmonary endarterectomy according to the changing features of chronic thromboembolic pulmonary hypertension patients during 17-year single-center experience. J Thorac Cardiovasc Surg. 2012;144: $100-7$

\title{
Parenchymal-sparing bronchoplasty: A rare surgical approach
}

\author{
Craig Moores, MD, and Darroch Moores, MD, FACS, New Haven, Conn
}

Sleeve lobectomy is a widely accepted surgical approach. One benefit provided by sleeve lobectomy is the salvage of lung parenchyma. This increases its usefulness in patients with seriously limited pulmonary reserve following pneumonectomy. A recent study ${ }^{1}$ determined that wedge bronchoplasty may provide the advantage of decreased postoperative strictures, and preserves native bronchial blood supply without adverse oncologic outcomes. Here, we provide a case report of parenchymal-sparing bronchoplasty that we believe offers the advantage of decreased operative morbidity, preservation of pulmonary reserve, and preservation of native blood supply.

From Yale New Haven Hospital, New Haven, Conn.

Disclosures: Authors have nothing to disclose with regard to commercial support.

Received for publication June 19, 2012; revisions received Aug 22, 2012; accepted for publication Dec 11, 2012; available ahead of print Jan 14, 2014.

Address for reprints: Craig Moores, MD, 50 Elihu St, New Haven, CT 06517 (E-mail: moores.craig@gmail.com).

J Thorac Cardiovasc Surg 2013;145:1410-1

$0022-5223 / \$ 36.00$

Copyright (c) 2013 by The American Association for Thoracic Surgery

http://dx.doi.org/10.1016/j.jtcvs.2012.12.052

\section{CLINICAL SUMMARY}

A 19-year-old man presented to our practice following a syncopal episode and reports of chronic cough. A chest radiograph showed right lower lobe atelectasis. A follow-up computed tomography scan of the chest showed a soft tissue density obliterating the bronchus intermedius with associated complete collapse/consolidation of the right middle and right lower lobes. A flexible bronchoscopy with endobronchial biopsy showed complete obstruction of the proximal bronchus intermedius caused by a low-grade mucoepidermoid tumor.

The following day the patient underwent rigid bronchoscopy with partial endoscopic resection of the tumor. The procedure was terminated due to bleeding and the patient underwent a second debulking 5 days later. It was evident that the tumor arose from the medial aspect of the bronchus intermedius, extending from the level of the right upper lobe distally to the middle lobe orifice (Figure 1). Following debulking, the bronchus intermedius as well as the middle and lower lobe orifices were widely patent. The hope was that the lower and middle lobe atelectasis would resolve with time to allow for a subsequent parenchymal-sparing bronchial sleeve resection. Resolution of atelectasis would result 

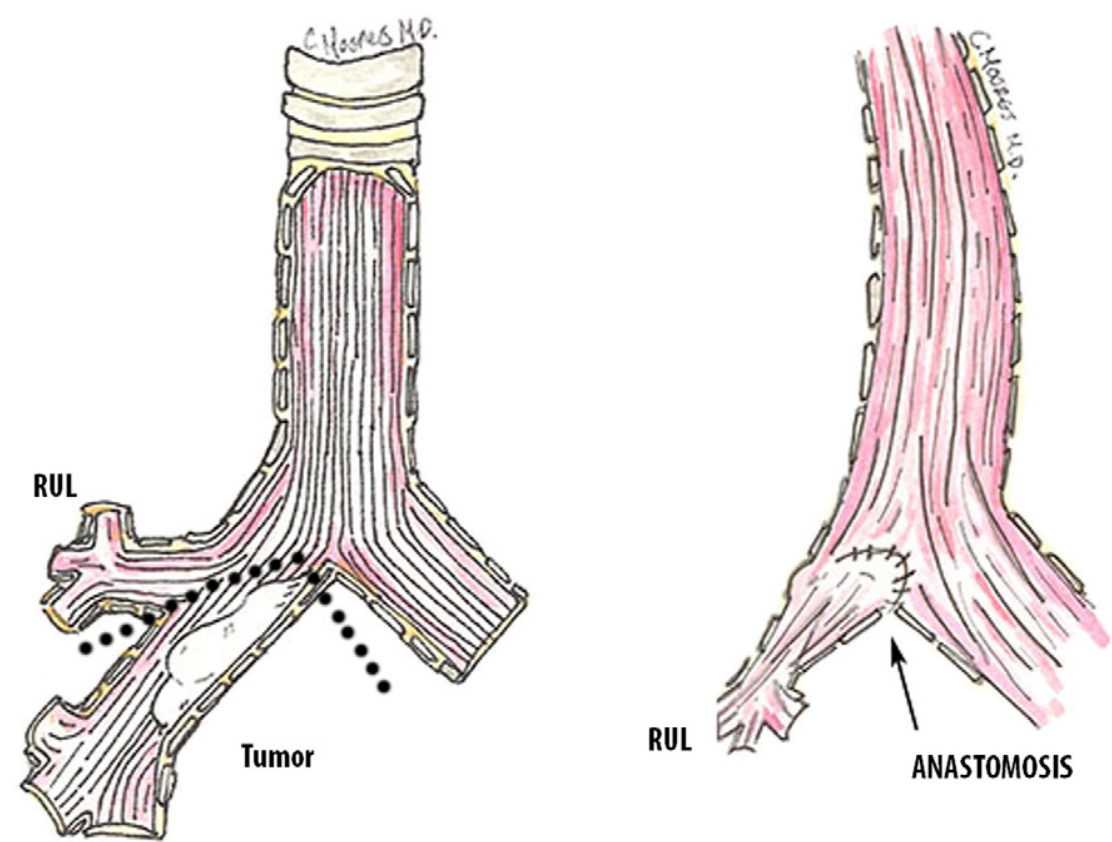

FIGURE 1. Pre- and postoperative anatomy. Left, Image of bronchus showing location of muchoepidermoid tumor in bronchus intermedius before resection. The doted line marks the resection. Right, Image of an airway following anastomosis. RUL, Right upper lobe bronchus.

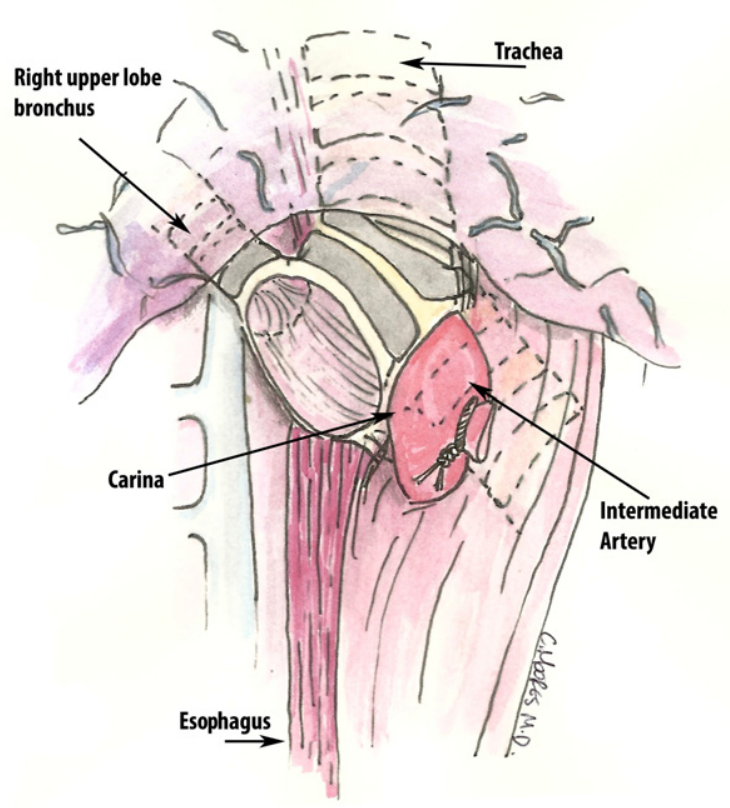

FIGURE 2. Image of an airway following complete resection of a tumor and right middle and lower lobes. Closing of the airway in an anterior to posterior fashion would result in stricture of the right upper lobe. Closure was performed in a superior to inferior fashion, thereby anastomosing the right upper lobe bronchus to the carina.

in sparing the lower and possibly middle lobe. A computed tomography scan of the chest performed 6 weeks following the initial presentation showed severe bronchiectasis and complete atelectais in the right middle and lower lobes and they were therefore deemed unsalvageable.

The patient was taken to the operating room for an intended bilobectomy later that week. At the time of surgery, the middle and lower lobes were completely atelectatic. Division of the bronchus intermedius at the level of the right upper lobe spur was undertaken. The margin of resection of the right main bronchus yielded a visible tumor and a positive margin of resection medially. A standard bilobectomy was therefore impossible. Rather than perform a pneumonectomy, we elected to resect the medial aspect of the right main bronchus (Figure 2) and attach the upper lobe to the carina (Figure 1). Using an interrupted anastomosis of 3-0 Vicryl (Ethicon Inc, Somerville, NJ), we were able to salvage the viable upper lobe. All branches of the pulmonary artery to the right upper lobe were preserved, including the recurrent branch. The patient made an uneventful recovery and was discharged from the hospital at postoperative day 4. On final pathology all margins were grossly and microscopically negative. The tumor was stage IIB (T3N0). On 3-month follow-up a bronchoscopy showed the anastomosis to be well healed, the airway was patent, and the right upper lobe was fully expanded.

\section{Reference}

1. Park SE, Lee HS, Jang HJ, Joo J, Kim MS, Jong ML, et al. Wedge bronchoplastic lobectomy for non-small cell lung cancer as an alternative to sleeve lobectomy. J Thorac Cardiovasc Surg. 2011;143:825-31. 